Tropical Journal of Pharmaceutical Research March 2017; 16 (3): 581-588

ISSN: $1596-5996$ (print); 1596-9827 (electronic)

(C) Pharmacotherapy Group, Faculty of Pharmacy, University of Benin, Benin City, 300001 Nigeria.

All rights reserved.

Available online at http://www.tjpr.org

Original Research Article

http://dx.doi.org/10.4314/tjpr.v16i3.12

\title{
Therapeutic effects of Saikosapoin D on bleomycin- induced pulmonary fibrosis in mice via regulation of IL- 33/ST2 pathway
}

\author{
Jiao Xu ${ }^{1}$, Xiao-hui Miao ${ }^{1}$, Jin-Xu Zheng ${ }^{2}$, Ming Ding ${ }^{2}$ and Zhi-fang Zhuang ${ }^{1 *}$ \\ ${ }^{1}$ Department of Respiratory, Changzhou Wujin People's Hospital, Chang Zhou 213017, ${ }^{2}$ Department of Respiratory, Affiliated \\ Hospital of Jiang Su University, Zhen Jiang 212000, China
}

*For correspondence: Email: zhuangzfcdy@126.com; Tel/Fax: +86-0519-85336190

Received: 3 September 2016

Revised accepted: 10 February 2017

\begin{abstract}
Purpose: To investigate the therapeutic effects of saikosapoin D (SSD) on bleomycin (BLM)-induced pulmonary fibrosis (PF) in mice and its probable mechanisms.

Methods: PF mice were prepared by intraperitoneal (i.p.) injection of BLM $(5 \mathrm{mg} / \mathrm{kg})$. Twenty-four hours later, 72 mice in SSD group were administered SSD (1.8 mg/kg, ip). After 3, 7, 14 and 28 days of injection, the mice were sacrificed. Blood samples and lung tissues were collected from 6 mice in each group. The lung tissues were subjected to histological examination. In addition, expressions of MyD88, TRAF6, IL-33 and ST2 in lung tissue were determined by western blotting assay. Serum levels of hydroxyproline (HYP), interleukin (IL)-4, IL-13 and interferon (IFN)-y were measured by enzyme-linked immunosorbent assay (ELISA).

Results: Pathological results showed that SSD treatment alleviated alveolitis and lung fibrosis $(p<$ $0.05)$ in lung tissues of PF mice at 14 and 28 days post-BLM injection. HYP and IL-13 levels of mice in SSD group were significantly lower than that in BLM group at days 14 and 28 post-BLM injection ( $p<$ 0.05). Levels of IL-4 and IFN-y were significantly lower when compared with values in BLM group on day $28(p<0.05)$. Western blotting results revealed that expressions of MyD88, TRAF6, IL-33 and ST2 proteins were significantly decreased by SSD treatment $(p<0.05)$.

Conclusion: SSD exerts therapeutic effects on BLM-induced experimental PF in mice via regulation of IL-33/ST2 pathway.
\end{abstract}

Keywords: Saikosapoin D, Idiopathic pulmonary fibrosis, Myeloid differentiation factor, Hydroxyproline, Interleukin, Interferon, IL-33/ST2 pathway

Tropical Journal of Pharmaceutical Research is indexed by Science Citation Index (SciSearch), Scopus, International Pharmaceutical Abstract, Chemical Abstracts, Embase, Index Copernicus, EBSCO, African Index Medicus, JournalSeek, Journal Citation Reports/Science Edition, Directory of Open Access Journals (DOAJ), African Journal Online, Bioline International, Open-J-Gate and Pharmacy Abstracts

\section{INTRODUCTION}

Idiopathic pulmonary fibrosis (IPF) is a common and complex disease with high mortality and morbidity, and the median survival time is only 2 to 5 years [1,2]. Recent findings indicate that the mechanisms of its fibrotic effect involve transforming growth factor- $\beta$ (TGF- $\beta$ ), Wnt ligands (secreted glycoproteins), toll-like receptor mediated signaling and type 2 immune responses, [3,4]. In addition, current clinical trials have evaluated various therapeutic approaches for IPF, such as dual endothelin receptor antagonist bosentan, imatinib, sildenafil, etanercept and interferon-c-1 $\beta$, etc [5-7]. However, none of these ways attained the primary aims. Currently, the combination of corticosteroids and immunosuppressants is considered as common strategy for IPF 
treatment, however it would bring some serious adverse effects [8].

A novel signaling named IL-33/ST2 has been studied in many other fibrotic diseases, such as scleroderma, progressive systemic sclerosis and liver fibrosis $[9,10]$. ST2, an interleukin (IL)-1 receptor-related protein, is specifically expressed on Th2 cells, mast cells but not on Th1 cells, and has been recognized as a stable marker of Th2 cells [11]. IL-33, a novel member of IL-1 family, takes on its biologic activations by combining with its receptor protein ST2 [12].

Saikosapoin D (SSD) is an active constituent of Radix Bupleuri which is a famous herbal medicine in China with broad spectrum bioactivities. Previous reports indicated that SSD could be used to treat hepatic fibrosis and inflammatory diseases [13,14]. Thus, in the present investigation, we evaluated the potential therapeutic effects of SSD on bleomycin (BLM)induced pulmonary fibrosis (PF) in mice, and the role of IL-33/ST2 pathway in this process.

\section{EXPERIMENTAL}

\section{Chemicals and reagents}

Saikosapoin-D (SSD) was purchased from the Jiangxi Herbfine Science and Technology Co. Ltd (Jiangxi, China); chloral hydrate was obtained from the Jiangbin Hospital (Zhenjiang, China); Bleomycin (BLM) was purchased from the Nippon Kayaku Co., Ltd. (Tokyo, Japan); Hematoxylin and Eosin (H\&E), Masson's Trichrome, hydroxyproline (HYP) commercial kit, tissue RIPA buffer, primary antibodies for myeloid differentiation factor 88 (MyD88) and $\beta$ actin were purchased from the Wuhan Boster Biotech Co. (Wuhan, China); PVDF membranes and skimmed milk powder were obtained from the Millipore Co. Ltd. (Billerica, MA, America); primary tumor necrosis factor (TNF) receptorassociated factor 6 (TRAF6) monoclonal antibody was purchased from the Santa Cruz (Shanghai, China); commercial ELISA kits for IL4, IL-13, IFN-y and primary IL-33 monoclonal antibody were products of R\&D. Inc. (Shanghai, China); primary ST2 polyclonal antibody was purchased from the Abcam Co. (Cambridge, UK); HRP-conjugated secondary antibody was purchased from the Cwbiotech. Co. (Shanghai, China).

\section{Animals}

SPF female C57BL/6 stain mice (6 weeks old, 18 $\pm 2 \mathrm{~g}$ ) were purchased from the Laboratory Animal Center of Jiangsu University (Zhenjiang,
China). All the animal experimental protocols were performed in accordance with the National Principles of Care and Use of Laboratory Animals [15] and were approved by the Ethics Committee of Changzhou Wujin People's Hospital (no. 2015a-4\#A).

\section{Animal model establishment and experimental protocols}

A total of 72 mice were evenly divided into three groups ( $\mathrm{n}=24)$ : control group (Cont.), BLM group and SSD group. After anaesthetized wtih chloral hydrate by intraperitoneal injection (0.01 $\mathrm{mg} / \mathrm{kg}$ body weight, ip), mice in the BLM and SSD groups were injected with bleomycin (5 $\mathrm{mg} / \mathrm{kg}$, body weight, ip), while mice in control group were given equivalent volume of saline in place of bleomycin. Twenty-four hour after BLM injection, SSD mice were administered SSD (1.8 $\mathrm{mg} / \mathrm{kg}$ body weight, ip). On day 3, 7, 14 and 28 after bleomycin injection, blood samples were collected using orbital blood sampling, and subsequently 6 mice of each group were sacrificed by cervical dislocation and the lung tissues were excised. The left lung tissues were fixed with $4 \%$ paraformaldehyde, while the right lung tissues were frozen in liquid nitrogen for 10 min and then stored at $-70^{\circ} \mathrm{C}$.

\section{Histopathological investigations}

The left lung tissues, fixed with $4 \%$ paraformaldehyde, were paraffin embedded, and successively sliced at $4 \mu \mathrm{m}$ thickness. The slices were stained with $H \& E$ to detect the degrees of inflammation and injury, while some were stained with Masson's Trichrome to detect extent of fibros. According to methods established by Szapiel et al, score of 1, 2, 3, and 4 indicate grade $0,1,2$, and 3 of alveolitis or pulmonary fibrosis was calculated [16].

\section{Determination of HYP contents in lung tissues}

The right lung tissues were used to determine the HYP contents according to the instruction on commercial HYP kits.

\section{Western blotting assay}

Lung tissues were homogenized and lysed with RIPA buffer and subsequently the total proteins were isolated. Then, equal amounts $(30 \mu \mathrm{g})$ of protein were separated by SDS - PAGE and transferred to PVDF membranes. The procedures used followed the sequence: blocking with skimmed milk powder, incubation with primary polyclonal antibodies (including 
MyD88, TRAF6, IL-33 and ST2), and addition of HRP-conjugated secondary antibody. $\beta$-actin was used as internal control, and specific bands were visualized using ECL chemiluminescence kit (GE Healthcare, USA).

\section{Determination of serum levels of IL-4, IL-13 and IFN-Y}

Blood samples were treated with heparin sodium and then stored at $-70{ }^{\circ} \mathrm{C}$. After blood sample were centrifuged, serum levels of IL-4, IL-13 and IFN- $\gamma$ were measured by commercial ELISA kits according to the manufacturer's instructions.

\section{Statistical analysis}

Data are presented as mean \pm standard deviation (SD). Statistical significance of differences between groups was determined with SPSS 16.0 statistical software, using one-way analysis of variance (ANOVA) followed by LSD test (equal variances assumed) or GamesHowell test (Equal Variances not assumed). $P<$ 0.05 was accepted as statistically significant.

\section{RESULTS}

\section{Pathological changes in lung tissues}

The architectures of lung tissues of mice in control group were normal without obvious inflammatory cells and fiber collagen proliferation (Figures 1\&2). As can be seen from Figure 1B -
$1 \mathrm{E}$, mild alveolitis was observed in BLM mice on day 3 after BLM injection; on day 7, the alveoli architectures was extensively broken, with evidence of high level of inflammation, and presence of inflammatory cells and erythrocytes in both septum and alveolus. Collagen fibers were few. The degree of inflammation on day 14 was milder, but the alveolus were collapsed and fused with extensive collagen fiber proliferation. On day 28, mild inflammation was observed, but the architectures of alveolus were blurred, with wild broad-band collagen fiber, and diffuse lung fibrosis. The degree of alveolitis in SSD mice on day 3 was not different from that of mice in BLM group. Interestingly, alveolitis in SSD-treated mice on day 7 was less than that of the BLMtreated mice. On day 28, the extent of alveolitis in SSD mice was less than that in BLM mice, with fewer collagen fibers. However broken and disordered architectures was still evident (Figure 2).

There were significant differences on days 3,7 , 14 and 28 in grades of alveolitis in BLM and SSD groups compared to control group $(p<0.05$, Table 1). However, the alveolitis of SSD-treated mice were milder than that of BLM mice at all time points, with significant differences on day 28 $(p<0.05$, Table 1). Compared to control group, fibrosis grades of both BLM and SSD mice significantly different on days 7,14 and $28(p<$ 0.05 , Table 1).

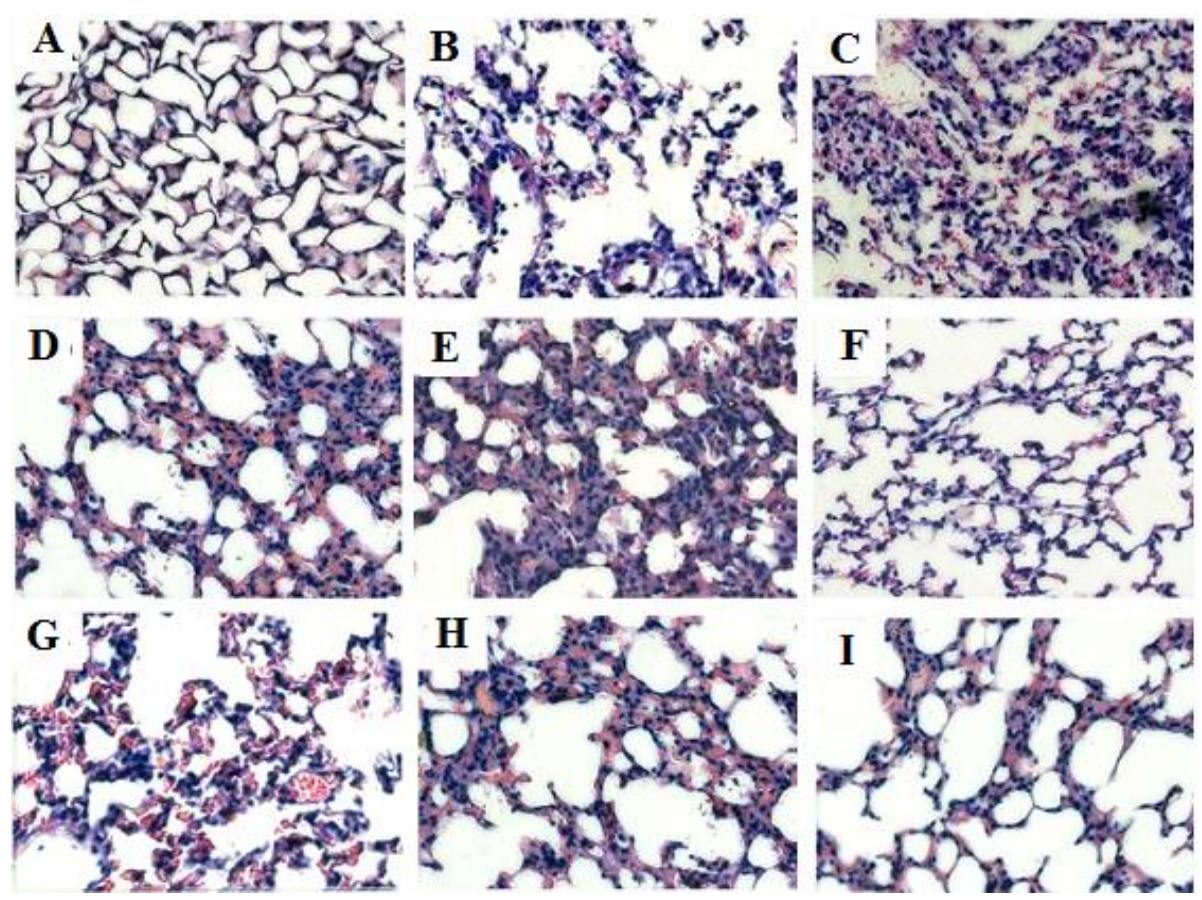

Figure 1: Histopathological changes in lung tissues (H\&E). Cont. denotes control; A-I represent tCont. (3 day), $\operatorname{BLM}(3,7,14$ and 28 day) and SSD groups (3, 7, 14 and 28 day), respectively 

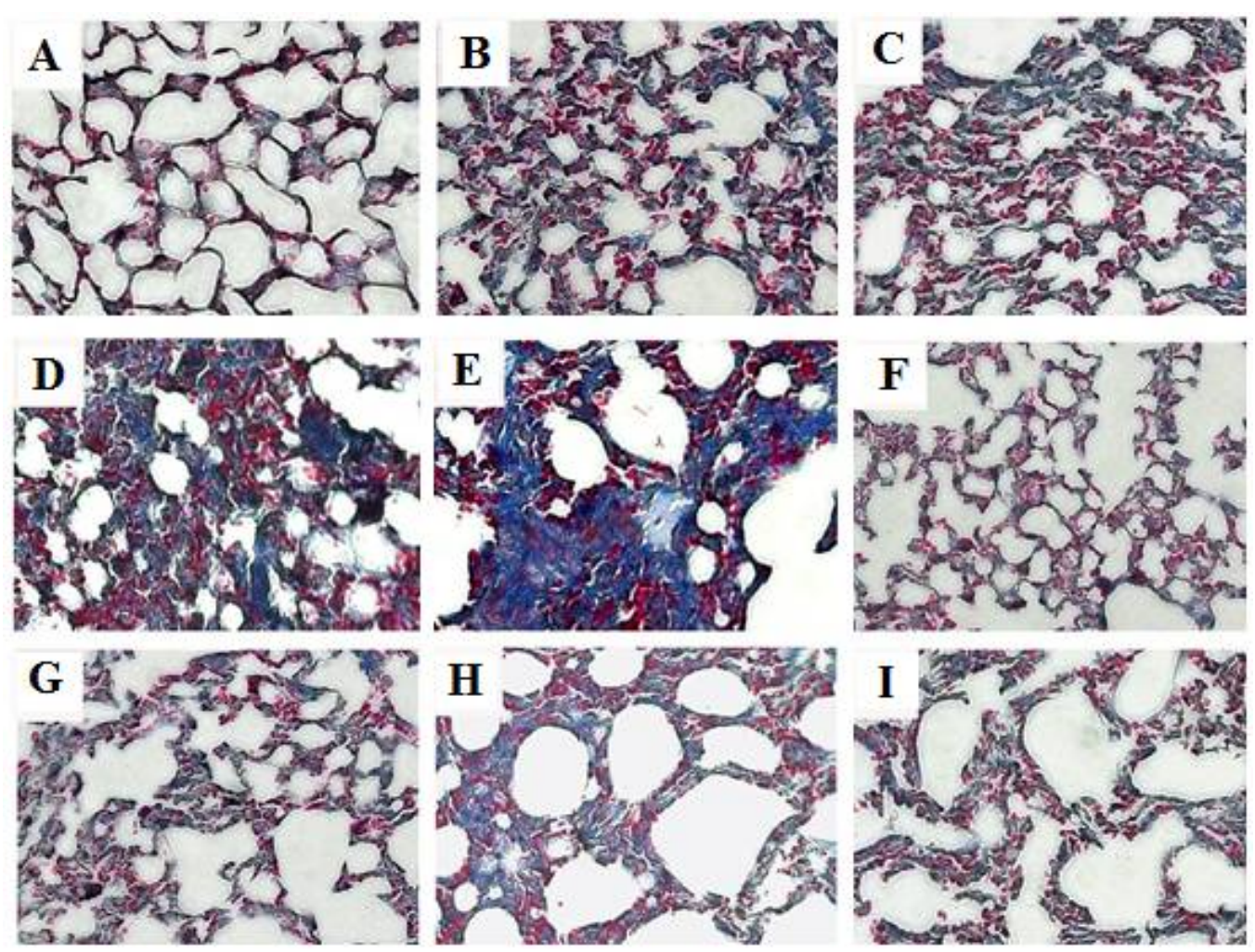

Figure 2: Pathological changes in lung tissues (Masson's Trichrome staining). Cont. = control. A-I represents Cont. (3 day), BLM (days 3, 7, 14 and 28) and SSD groups (days 3, 7, 14 and 28), respectively

Table 1: Degrees of alveolitis and lung fibrosis

\begin{tabular}{lcccccccc}
\hline \multirow{2}{*}{ Variable } & \multicolumn{2}{c}{ 3d } & \multicolumn{2}{c}{ 7d } & \multicolumn{2}{c}{ 14d } & \multicolumn{2}{c}{ 28d } \\
& Alveolitis & Fibrosis & Alveolitis & Fibrosis & Alveolitis & Fibrosis & Alveolitis & Fibrosis \\
\hline Cont. & $1.00 \pm 0.00$ & $1.00 \pm 0.00$ & $1.00 \pm 0.00$ & $1.00 \pm 0.00$ & $1.00 \pm 0.00$ & $1.00 \pm 0.00$ & $1.00 \pm 0.00$ & $1.00 \pm 0.00$ \\
BLM & $2.73 \pm 0.21^{*}$ & $1.10 \pm 0.13$ & $3.63 \pm 0.15^{*}$ & $1.52 \pm 0.26^{*}$ & $2.73 \pm 0.18^{*}$ & $2.85 \pm 0.15^{*}$ & $1.40 \pm 0.10^{*}$ & $3.58 \pm 0.19^{*}$ \\
SSD & $2.32 \pm 0.10^{* \#}$ & $1.13 \pm 0.06$ & $3.03 \pm 0.15^{* \#}$ & $1.53 \pm 0.20^{*}$ & $2.47 \pm 0.21^{* \#}$ & $2.47 \pm 0.20^{* \#}$ & $1.13 \pm 0.06^{* \#}$ & $2.15 \pm 0.18^{* \#}$ \\
$F$ & 136.050 & 2.08 & 367.357 & 7.758 & 179.347 & 135.487 & 28.000 & 220.622 \\
$p$ & $<0.01$ & 0.206 & $<0.01$ & 0.022 & $<0.01$ & $<0.01$ & $<0.01$ & $<0.01$ \\
\hline \multicolumn{7}{l}{ Cont. $=$ control. Data are expressed as Mean $\pm S D(n=6) ;{ }^{*} p<0.05$ vs control group, and ${ }^{\#} p<0.05$ vs $B L M$} \\
group
\end{tabular}

Table 2: HYP volume in lung tissue $(\mathrm{mg} / \mathrm{g})$

\begin{tabular}{lcccc}
\hline Variable & $\mathbf{3 d}$ & $\mathbf{7 d}$ & $\mathbf{1 4 d}$ & $\mathbf{2 8 d}$ \\
\hline Cont. & $0.773 \pm 0.023$ & $0.779 \pm 0.011$ & $0.770 \pm 0.033$ & $0.774 \pm 0.007$ \\
BLM. & $0.799 \pm 0.034$ & $1.082 \pm 0.026^{*}$ & $1.251 \pm 0.031^{*}$ & $1.386 \pm 0.019^{*}$ \\
SSD & $0.776 \pm 0.025$ & $0.940 \pm 0.053$ & $1.007 \pm 0.015^{\star \#}$ & $1.205 \pm 0.008^{\text {*\# }}$ \\
\hline$F$ & 0.837 & 57.65 & 231.377 & 1905 \\
$p$ & 0.478 & $<0.01$ & $<0.01$ & $<0.01$ \\
\hline
\end{tabular}

Data are expressed as mean $\pm S D(n=6) ;{ }^{*} p<0.05$ vs control group, and ${ }^{\#} p<0.05$ vs BLM group.

(Cont. $=$ control)

\section{HYP levels in lung tissues}

The concentrations of HYP in lung tissues from both BLM and SSD groups increased and reached the peak on day 28 . There were significant differences on days 7,14 and 28 in BLM group, compared to control group $(p<0.05$, Table 2).); while the levels of HYP in SSD group were less than that in BLM group from day 7 , and became significantly different on days 14 and 28 $(p<0.05$, Table 2).

\section{Expressions of IL-33, ST2, MyD88 and TRAF6 in lung tissues}

Compared to control group, the protein levels of ST2, MyD88 and TRAF6 in BLM mice increased as from day 3 , with significant increases on days 
$3,7,14$ and $28(p<0.05)$; while the protein levels in SSD mice increased initially, peaked on day 7 , and subsequently decreased. Significant differences ST2 between this group and control were obtained on days 3,7 and 14 , and on days 14 and 28 relative to the BLM group ( $p<$ 0.05 ). There were significant differences in MyD88 between the SSD group and control days 3 and 7, and between the SSD and BLM groups on days14 and $28 \quad(p<0.05)$. Significant differences in TRAF6 between the SSD group and controls were obtained at all times points control group $(p<0.05)$, while on days 14 and 28 versus BLM group $(p<0.05)$ (Figure 3$)$. The IL33 level increased firstly then decreased gradually, with its peak on day 7 . Significant differences were observed on days 3,7 and 14 in BLM mice, relative to control and SSD mice $(p<$ 0.05); while compared to control group, there were significant differences on days 14 and 28 in SSD group $(p<0.05$, Figure 3$)$.

\section{Serum levels of IL-4, IL-13 and IFN-y}

The concentrations of IL-4, IL-13 increased from day 7 , and became significantly higher on days 7,14 and 28 relative to control group $(p<0.05)$; there were significant differences in IL-4 between the BLM and SSD groups on day $28(p<0.05)$, while for the same groups, IL-13 levels differed significantly on days 14 and $28(p<0.05)$ (Figure
4). Values of IFN- $y$ in BLM and SSD groups rose from day 7 and peaked on day 14, with the same significant differences on days 7,14 and 28 relative to control group $(p<0.05)$; meanwhile, at every time point, the levels of IFN- $\gamma$ in SSD group were higher than that in BLM group, and significant differences were obtained on day 28 between two groups $(p<0.05)$ (Figure 4$)$.

\section{DISCUSSION}

Bleomycin (BLM), an anti-neoplastic antibiotic is a derivative of Streptomyces verticillus with severe side-effects as inflammation and fibrosis specific to the lung [17]. To the best of our knowledge, no suitable treatment exists for lung fibrosis currently. Animal models are important the investigation of pathological mechanisms and preclinical evaluation of novel therapies. Therefore, bleomycin-elicited injury in small rodents have been become the traditional and most commonly adopted lung fibrosis model [18]. The results showed that when the lung exposed to bleomycin, there were damages to the lung tissues, accompanying some epithelial or endothelial cells over-apoptosis passively respond to the injury. In addition, the SSD could be used to effectively ameliorate the damages induced by bleomycin.

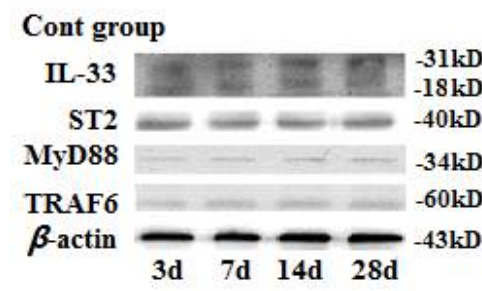

BLM group
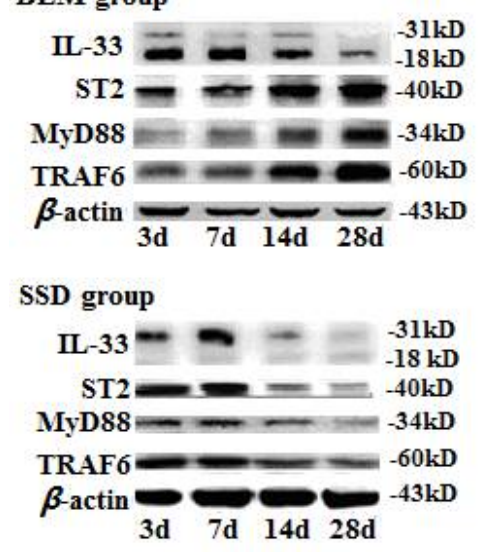

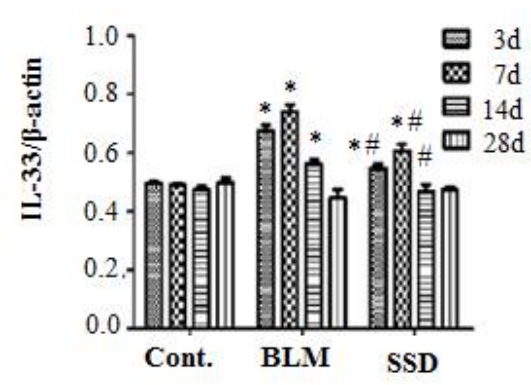

D

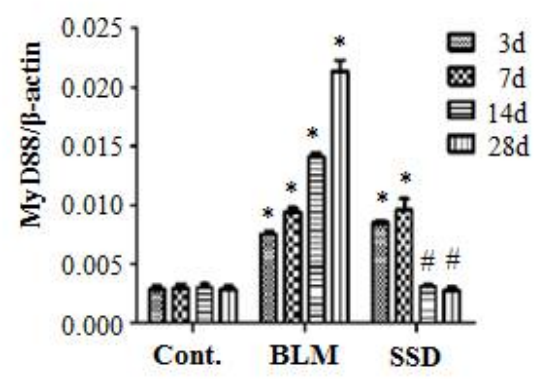

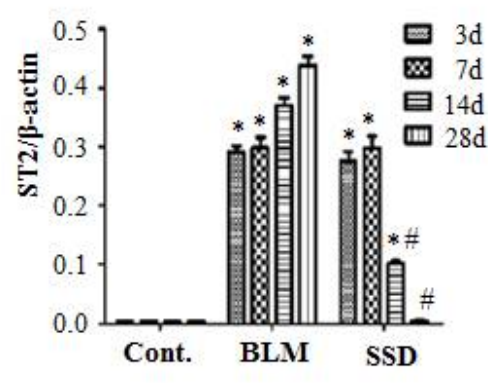

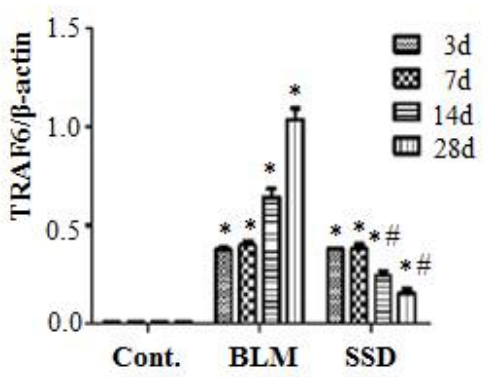

Figure 3: Expressions of IL-33, ST2, MyD88 and TRAF6 in lung tissues. $\beta$-actin was used as internal control, and the expressions of IL-33, ST2, MyD88 and TRAF6 in lung tissues were detected by western blotting analysis. Cont. means control. Data were expressed as Mean $\pm \mathrm{SD},{ }^{*} p<0.05$ vs control group, and ${ }^{\#} p<0.05$ vs BLM group 

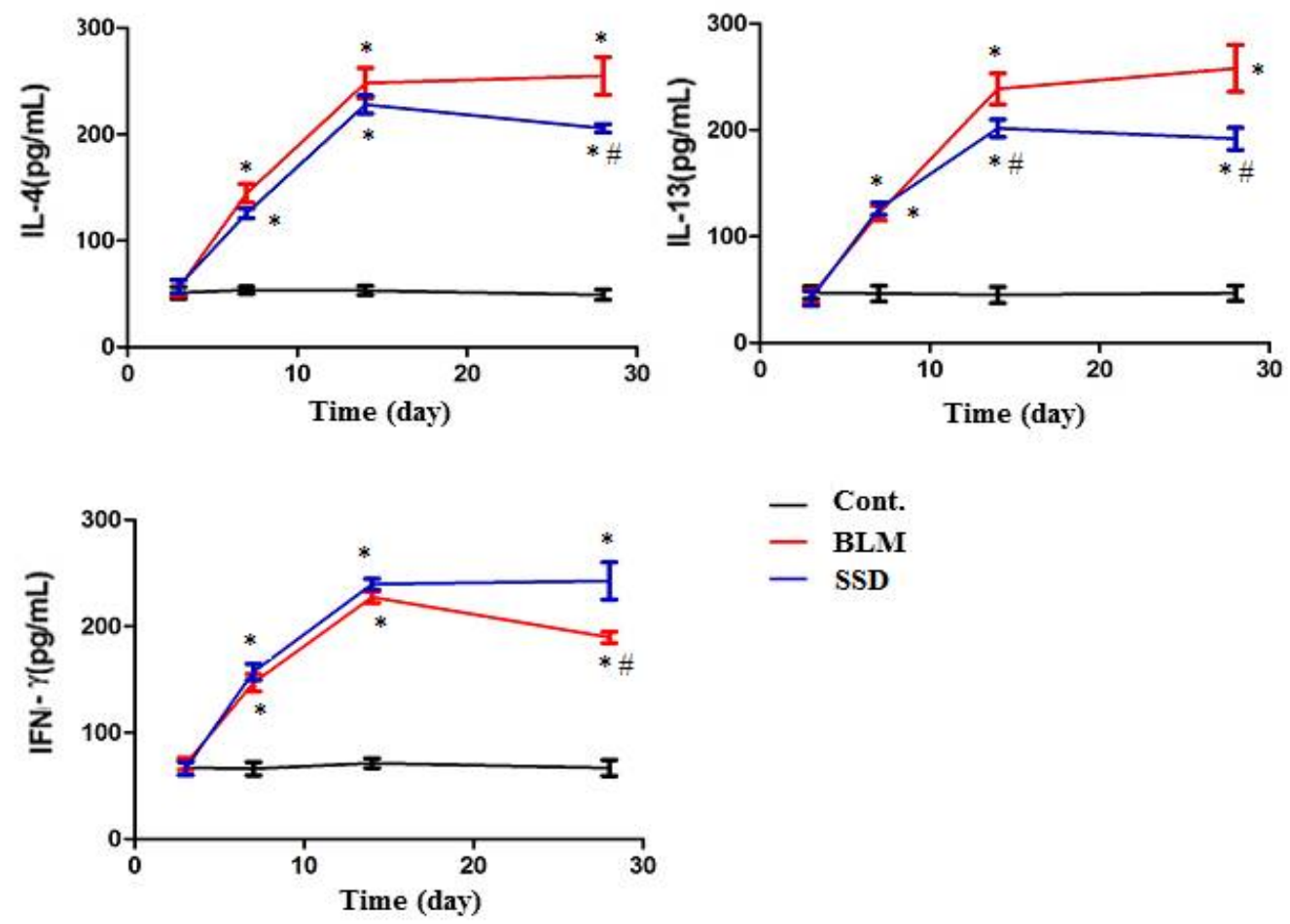

Figure 4: Levels of IL-4, IL-13 and IFN-y in serum. Cont. means control. Data were expressed as Mean \pm SD; ${ }^{*} p<0.05$ vs control group, ${ }^{\#} p<0.05$ vs BLM group.

IL-33, as an 'alarmin', was secreted from the injured cells. This study further detected MyD88 and TRAF6, the down-stream molecules of ST2, which can ultimately lead to the activation of NF $\mathrm{KB}$ and MAP kinases involved in the control of cellular proliferation and apoptosis [12]. Expressions of protein MyD88 and protein began to increase from day3 post-model, and attained maximum levels on day 28, with similar trends for protein ST2, IL-4 and IL-13. IL-4 and IL-13 are two major cytokines of Th2 cells, which can involve fibrogenesis by up-regulating proteins associated with wound healing, specifically arginase, collagens, matrix metalloproteinases (MMPs), and tissue inhibitors of MMP [19] or via recruiting $\mathrm{M} 2$ cells. In addition, they also could facilitate excessive tissue repair and fibrosis [20]. Therefore, from our results, it is speculated that IL-33 secreted from the dying or apoptosis cells via its receptor ST2 (a stable maker of Th2 cells). And IL-33 also amplified Th2-type responses and involved pulmonary fibrosis process. Whereas, compared to BLM group, the expressions of IL33 in lung tissues decreased from the day 3 , and still remained the same trends. Interestingly, levels of ST2, MyD88 and TRAF6 in SSD group increased firstly then decreased gradually, peaking on day 7 .

The dynamic changes in IL-4, IL-13 and IFN-Y further demonstrated that IL-33/ST2 signaling pathway was activated and a Th1/Th2 imbalance existed in the pulmonary fibrosis process. Herein, it revealed that corticosteroids, as conventional 'anti-inflammatory' therapy for fibrosis diseases, can disturb the expression of IL-33/ST2 signaling pathway and the balances of Th1 and Th2 cytokines. Nevertheless, more recent studies have adopted other methods to explore the role of IL-33/ST2 signaling pathway in many disorders. Mingcai $\mathrm{Li}$ et al demonstrated that blockage of IL-33/ST2 signaling pathway by antiIL-33 antibody can inhibit airway inflammation in a murine model of allergic asthma [21]. Hiroko Hayakawa et al showed that the antagonistic effects of soluble ST2 on IL-33 signaling using a murine thymoma EL-4 cells stably expressing ST2L and a murine model of asthma [22]. The results of present study demonstrated that the antibody or the soluble protein and corticosteroids exhibited impact on the IL-33/ST2 signaling pathway. Thus, the further investigations need to be done to find out the effective blocking agents for reducing the degree of fibrosis. To the best of our knowledge, the present study is the first to report that IL-33/ST2 signaling exist in a murine model of bleomycininduced pulmonary fibrosis. It is also the first study that to report that Saikosapoin-D has some degree of interference in IL-33/ST2 signaling pathway, compared to other studies that found that IL-33/ST2 signaling pathway was interfered by anti-IL-33 antibody [21] or soluble ST2 [22], or administration of IL-33 [23]. 


\section{CONCLUSION}

These findings demonstrate that SSD is a potential candidate for treating IPF via downregulation of IL-33/ST2 signaling. In addition, the results also suggest that IL-33/ST2 signaling pathway is a potential drug target for treating IPF.

\section{DECLARATIONS}

\section{Acknowledgement}

This work was supported by grants from Scientific Research Program of Ministry of Public Health (no. WKJ2006-2-026) and Natural Science Foundation of Shanghai (no. 10ZR1422600). The authors thank $\mathrm{Dr} \mathrm{Lu}$ Rongzhu and $M$ Wang Shizhong for their excellent technical assistance.

\section{Conflict of Interest}

No conflict of interest associated with this work.

\section{Contribution of Authors}

The authors declare that this work was done by the authors named in this article and all liabilities pertaining to claims relating to the content of this article will be borne by them.

\section{Open Access}

This is an Open Access article that uses a funding model which does not charge readers or their institutions for access and distributed under the terms of the Creative Commons Attribution License (http://creativecommons.org/licenses/by 14.0) and the Budapest Open Access Initiative (http://www.budapestopenaccessinitiative.org/rea d), which permit unrestricted use, distribution, and reproduction in any medium, provided the original work is properly credited.

\section{REFERENCES}

1. du Bois RM. Idiopathic pulmonary fibrosis: present understanding and future options. Eur Respir Rev 2011; 20: 132-133.

2. Vancheri C, Failla M, Crimi N, Raghu G. Idiopathic pulmonary fibrosis: a disease with similarities and links to cancer biology. Eur Respir J 2010; 35: 496-504.

3. Navarro-Partida J, Martinez-Rizo AB, Gonzalez-Cuevas $J$, Arrevillaqa-Boni G, Ortiz-Navarrete V, ArmendarizBorunda J. Pirfenidone restricts Th2 differentiation in vitro and limits Th2 response in experimental liver fibrosis. Eur J Pharmacol 2012; 678: 71-77.
4. Seki E, Park E, Fujimoto J. Toll-like receptor signaling in liver regeneration, fibrosis and carcinogenesis. Hepatol Res 2011; 41: 597-610.

5. Daniels CE, Lasky JA, Limper AH, Mieras K, Gabor E, Schroeder DR. Imatinib treatment for idiopathic pulmonary fibrosis: randomized placebo-controlled trial results. Am J Respir Crit Care Med 2010; 181: 604-610.

6. King TE, Albera C, Bradford WZ, Costabel U, Hormel P, Lancaster $L$. Effect of interferon gamma-1b on survival in patients with idiopathic pulmonary fibrosis (INSPIRE): a multicentre, randomised, placebo-controlled trial. Lancet 2009; 374: 222-228.

7. Zisman $D A$, Schwarz $M$, Anstrom $K J$, Collard $H R$, Flaherty KR, Hunninghake GW. A controlled trial of sildenafil in advanced idiopathic pulmonary fibrosis. $N$ Engl J Med 2010; 363: 620-628.

8. Costabel U. Emerging potential treatments: new hope for idiopathic pulmonary fibrosis patients? Eur Respir Rev 2011; 20: 201-207.

9. Manetti M, Ibba-Manneschi L, Liakouli V. The IL-1-like cytokine IL-33 and its receptor ST2 are abnormally expressed in the affected skin and visceral organs of patients with systemic sclerosis. Ann Rheum Dis 2010; 69: 598-605.

10. Marvie P, Lisbonne, M, L'Helgoualc'h A, Rauch M, Turlin $B$, Preisser L, Bourd-Boittin K, Théret N. Interleukin-33 over-expression is associated with liver fibrosis in mice and humans. J Cell Mol Med 2010; 14: 1726-1739.

11. Löhning $M$, Stroehmann A, Coyle J, Grogan JL, Lin S, Gutierrez-Ramos JC, Levinson D, Radbruch A, Kamradt T. T1/ST2 is preferentially expressed on murine Th2 cells, independent of interleukin 4, interleukin 5, and interleukin 10, and important for Th2 effector function, Proc Natl Acad Sci USA 1998; 95: 6930-6935.

12. Schmitz J, Owyang A, Oldham E. IL-33, an interleukin-1like cytokine that signals via the $\mathrm{L}-1$ receptor-related protein ST2 and induces $T$ helper type 2 associated cytokines. Immunity 2005; 23: 479-490.

13. He Y, Hu ZF, Li P, Xiao C, Chen YW, Li KM, Guo JZ, Pan $L$, Xiong JP. Experimental study of saikosaponin-d (SSd) on lipid peroxidation of hepatic fibrosis on rat. Chin J Chin Mater Med 2008; 33: 915-919.

14. Shi $Q$, Nie $S Q$, Huang $L Q$. New progression of chemical component and pharmacological studies of Radix Bupleuri. Chin J Exp Trad Med Formul 2002; 8: 53-56.

15. National Institutes of Health. Principles of Laboratory Animal Care, revised 1985, pp. 85-83.

16. Szapiel SV, Elson NA, Fulmer JD, Hunninghake GW, Crystal RG. Bleomycin-induced interstitial pulmonary disease in the nude, athymic mouse. Am Rev Respir Dis 1979; 120: 893-899.

17. O'sullivan JM, Huddart RA, Norman AR, Nicholls J, Dearnaley DP, Horwich $A$. Predicting the risk of bleomycin lung toxicity in patients with germ-cell tumours. Ann Oncol 2003; 14: 91-96.

18. Babin AL, Cannet C, Ge'rard C, Wyss D, Page CP, Beckmann N. Noninvasive assessment of bleomycininduced lung injury and the effects of short-term

Trop J Pharm Res, March 2017; 16(3): 587 
glucocorticosteroid treatment in rats using MRI. J Magn Reson Imag 2011; 33: 603-614.

19. Sandler NG, Mentink-Kane MM, Cheever AW, Wynn TA. Global gene expression profiles during acute pathogeninduced pulmonary inflammation reveal divergent roles for Th1 and Th2 responses in tissue repair. J Immunol 2003; 171: 3655-3667.

20. Rubartelli A, Lotze MT. Inside, outside, upside down: damage associated molecular-pattern molecules (DAMPs) and redox. Trends Immunol 2007; 28: 429436.
21. Liu X, Li M, Wu Y, Zhou Y, Zeng L, Huang T. Anti-IL-33 antibody treatment inhibits airway inflammation in a murine model of allergic asthma. Biochem Bio Res Commun 2009; 386: 181-185.

22. Hayakawa $H$, Hayakawa $M$, Kume A, Tominaga $S$. Soluble ST2 blocks interleukin-33 signaling in allergic airway inflammation. J Biol Chem 2007; 282: 2636926380.

23. Rankin AL, Mumm JB, Murphy E. IL-33 Induces IL-13dependent cutaneous fibrosis. J Immunol 2010; 184 : 1526-1535. 